\title{
A absorção de Nitrogênio, Fósforo, Potássio, Cálcio, Magnésio, Enxôfre e Silício pela cana de açúcar, Co 419, e o seu crescimento em função da idade. (*)
}

\author{
R. A. CATANI \\ E. S. A. "Luiz de Queiroz" \\ H. C. ARRUDA \\ Instituto Agronômico do Estado \\ D. PELEGRINO \\ E. S. A. "Luiz de Queiroz" \\ H. BERGAMIN F. ${ }^{0}$ \\ E. S. A. "Luiz de Queiroz"
}




\section{1 - INTRODUÇÃO}

As curvas de crescimento e de absorção de nutrientes pelas plantas cultivadas, em função de sua idade, fornecem informações básicas, de grande importância, sôbre as culturas estudadas. Fica-se, assim, conhecendo a quantidade de elementos absorvidos e a intensidade relativa de absorção dos nutrientes, durante o ciclo da cultura estudada.

Como consequência, são evidenciados os períodos que as plantas cultivadas absorvem, em maior proporção, os diversos elementos nutridores, resultando indicações úteis sôbre as épocas mais adequadas da aplicação de certos fertilizantes.

Assim, para a cultura do café, os dados obtidos nas condições do Estado de S. Paulo, por DAFERT (1895) e por CATANI \& MORAES (1958), forneceram informações úteis sôbre a quantidade de nutrientes, necessária para a formação e frutificação do cafeeiro.

Em relação ao estudo da nutrição da cana de açúcar, os trabalhos publicados são numerosos. Entretanto, grande parte dos mesmos tem cogitado mais da correlação entre o teor dos elementos nas fôlhas e a resposta à adubação, isto é, tem objetivado a "diagnose foliar" (CLEMENTS, 1951, 1955; CAPÓ, SAMUELS \& OUTROS, 1955; EVANS, 1955; COURY, MALAVOLTA \& OUTROS, 1957).

Os trabalhos referentes a outros aspectos da nutrição da cana de açúcar são também inúmeros e um resumo histórico dos mesmos foi publicado por VAN DILLEWIJN (1952). De acôrdo com os dados reunidos pelo citado autor, são muitas as contribuições apresentadas no sentido de fornecer conhecimentos sôbre a marcha do crescimento e a absorção de nutrientes pela cana, em diversas condições de clima e de solo, tais como as de Hawai, Mauritius, Barbados, Louisiana (Estados Unidos da América do Norte), Africa do Sul, etc.

O presente trabalho tem por objetivo o estudo da absorção de nitrogênio, fósforo, potássio, cálcio, magnésio, enxôfre e silício pela cana de açúcar, variedade Co 419 e o seu crescimento em função da idade da planta, nas condições de solo e clima de Piracicaba, Estado de S. Paulo.

\section{2 - MATERIAL E M屯TODOS}

Em abril de 1956, foi instalado um experimento na Estação Experimental de Cana, "Dr. José Vizioli", em Piracicaba, 
com a variedade Co 419, e que constou de 2 tratamentos, com 3 repetições. Um dos tratamentos foi denominado "sem adubo", isto é, a cana não foi adubada. O outro tratamento foi designado "adubado", porque na época do plantio da cana, foram aplicados, por hectare, $40 \mathrm{Kg}$ de $\mathrm{N}$ (em forma de sulfato de amônio), $100 \mathrm{Kg}$ de $\mathrm{P}_{2} \mathrm{O}_{5}$ (na forma de superfosfato simples) e $40 \mathrm{Kg}$ de $\mathrm{K}_{2} \mathrm{O}$ (na forma de cloreto de potássio).

$O$ solo em que foi instalado o experimento é uma terra roxa misturada, com as seguintes características:

$\%$ areia grossa $\ldots \ldots \ldots \ldots \ldots \ldots \ldots \ldots \ldots, \mathbf{8 , 4 0}$

$\%$ areia fina $\ldots \ldots \ldots \ldots \ldots \ldots \ldots \ldots \ldots .24,90$

$\%$ limo ..................... 16,40

$\%$ argila $\ldots \ldots \ldots \ldots \ldots \ldots \ldots \ldots \ldots \ldots \ldots, 50,20$

pH (em suspensão de $10 \mathrm{~g}$ de solo em $25 \mathrm{ml}$ de água destilada)

$\%$ C (g de carbono por $100 \mathrm{~g}$ de solo) $\ldots \ldots \ldots \ldots \quad 1,00$

$\% \mathrm{~N}$ (g de nitrogênio por $100 \mathrm{~g}$ de solo) $\ldots \ldots \ldots \quad 0,15$

e. $\mathrm{mg} \mathrm{PO}_{4}{ }^{-3}$ por $10 \mathrm{~g}$ de solo (solúvel em solução 0,05 normal de $\mathrm{H}_{2} \mathrm{SO}_{4}$ ) $\ldots \ldots \ldots \ldots \ldots \ldots \ldots, 0,06$

e. $\mathrm{mg} \cdot \mathrm{K}^{+}$trocável por $100 \mathrm{~g}$ de solo $\ldots \ldots \ldots \ldots \quad 0,18$

e. $\mathrm{mg} \mathrm{Ca} \mathrm{Ca}^{+2}$ trocável por $100 \mathrm{~g}$ de solo $\ldots \ldots \ldots \ldots \quad 2,00$

e. $\mathrm{mg} \mathrm{Mg}^{+2}$ trocável por $100 \mathrm{~g}$ de solo .......... 0,66

e. $\mathrm{mg} \mathrm{Mn+2}$ trocável por $100 \mathrm{~g}$ de solo (extraido com solução normal de $\mathrm{NaNO}_{3}$ ) $\ldots \ldots \ldots \ldots \ldots, 0,17$

e. $\mathrm{mg} \mathrm{H}+$ trocável por $100 \mathrm{~g}$ de solo ........ 5,28

capacidade de troca de cátions em e. $\mathrm{mg}$ por $100 \mathrm{~g}$ de solo (valor $\mathrm{t}$ ) $\ldots \ldots \ldots \ldots \ldots \ldots \ldots \ldots \ldots, \mathbf{8 , 2 9}$

indice de saturação em bases (valor i) ....... 36,30\%

As condições climáticas (temperatura e precipitação) do período em que se desenvolveu o experimento, acham-se resumidas no quadro 1. 
QUADRo 1 - Temperatura média mensal em gráus centígrados e precipitação mensal em milímetros, do período: janeiro de 1956 a agôsto de 1957, em Piracicaba, (E. S. A. "Luiz de Queiroz").

\begin{tabular}{|c|c|c|c|c|}
\hline \multirow{3}{*}{ Meses } & \multicolumn{4}{|c|}{$A N O S$} \\
\hline & \multicolumn{2}{|c|}{1956} & \multicolumn{2}{|c|}{1957} \\
\hline & $\underset{{ }^{\circ} \mathrm{C}}{\text { Temperatura }}$ & $\begin{array}{c}\text { Chuva } \\
\mathrm{mm}\end{array}$ & ${ }^{\circ} \mathrm{C}$ & $\underset{\mathrm{mm}}{\text { Chuva }}$ \\
\hline Janeiro & 26,7 & 60,8 & 23,6 & 313,6 \\
\hline Fevereiro & 24,2 & 136,9 & 23,1 & 128,3 \\
\hline Março ... & 23,7 & 47,1 & 23,1 & 185,6 \\
\hline Abril & 21,3 & 90,6 & 21,0 & 66,9 \\
\hline Maio ... & 17,0 & 114,5 & 18,5 & 4,2 \\
\hline Junho .. & 15,6 & 70,2 & 17,9 & 20,1 \\
\hline Julho $\ldots \ldots$ & 16,9 & 53,3 & 17,4 & 90,6 \\
\hline Agôsto & 17,3 & 74,0 & 19,5 & 51,7 \\
\hline Setembro & 21,8 & 72,7 & & \\
\hline Outubro & 21,8 & 72,6 & & \\
\hline Novembro & 22,2 & 23,1 & & \\
\hline Dezembro $\ldots$ & 24,0 & 137,0 & & \\
\hline
\end{tabular}

A partir de outubro de 1956, até julho de 1957, isto é, dos 6 meses até os 15 meses de idade, foram coletadas, mensalmente, as amostras de cana do campo. As amostras, constituidas de tôda a parte aérea de 4 touceiras completas de cada tratamento, depois de pesadas, foram preparadas para a análise.

Foram determinados nos colmos e fôlhas os seguintes teores: \% água, \% $\mathrm{N}, \% \mathrm{P}, \% \mathrm{~K}, \% \mathrm{Ca}, \% \mathrm{Mg}, \% \mathrm{~S}$ e \% $\mathrm{Si}$.

Os métodos analíticos empregados foram, em resumo, os seguintes: 


\section{NITROGÊNIO}

Este elemento foi determinado pelo método clássico de digestão do material sêco, com $\mathrm{H}_{2} \mathrm{SO}_{4}$ e $\mathrm{CuSO}_{4} .5 \mathrm{H}_{2} \mathrm{O}$ e posterior destilação do amoníaco, recebendo-o em solução de $\mathrm{H}_{2} \mathrm{SO}_{4}$, de normalidade conhecida. $\mathrm{O}$ excesso de $\mathrm{H}_{2} \mathrm{SO}_{4}$ foi determinado e a porcentagem de $\mathbf{N}$ foi calculada.

Silício, Potássio, Fósforo, Cálcio e Magnésio

Todos os elementos mencionados foram determinados na solução obtida após a incineração do material. A cinza foi preparada pelo aquecimento de $2,000 \mathrm{~g}$ do material sêco em cápsula de porcelana, à $500-550^{\circ} \mathrm{C}$, em forno e durante 45 a 60 minutos.

\section{SiLício}

Depois do material ter sido incinerado, a cinza foi tratada com $10 \mathrm{ml}$ de HC1 $(1+1)$ e deixou-se secar em banhomaria. Foram adicionados $2 \mathrm{ml}$ de $\mathrm{HCl}$, deixou-se secar e conservou-se em banho-maria durante 30-40 minutos. Foram adicionados $20 \mathrm{ml}$ de $\mathrm{HCl}(1+9)$, deixou-se aquecer para dissolver os sais. solúveis e filtrou-se, através de papel SS589, faixa azul, para um balão de $250 \mathrm{ml}$, lavando com água destilada até completar o volume (solução A). O papel de filtro, contendo o precipitado, foi incinerado à $850-900^{\circ} \mathrm{C}$ durante 1 hora e o $\mathrm{SiO}_{2}$ foi pesado.

\section{Potássio}

Este elemento foi determinado, ora pelo método do cobaltihexanitrito, ora pelo baseado em fotometria de chama.

Empregando-se o método do cobaltihexanitrito de potássio e sódio, foram pipetados $10 \mathrm{ml}$ de solução A (correspondentes a $80 \mathrm{mg}$ do material sêco), transferidos para uma cápsula de porcelana, e daquí por diante, seguiu-se a marcha analítica descrita em trabalho anterior, (CATANI, 1954).

No caso do método de fotometria de chama, o preparo da solução e o modo geral de trabalho foram idênticos ao já descrito, (CATANI, 1954), só que em lugar de usar o fotôme- 
tro Perkin-Elmer, modêlo 52-A, empregou-se o Espectrofotômetro Beckman, modêlo B, conjugado com os acessórios de fotometria de chama.

\section{FósForo}

O método da determinação do fósforo, baseado na formação do ácido molibdovanadofosfórico, tem sido recomendado por diversos autores, (KOENIG \& JOHNSON, 1942; KITSON \& MELLON, 1944 e BOLTZ \& LUECK, 1958). Foi empregado êsse método com modificações que 0 adaptassem às exigências do presente trabalho.

Pipetou-se uma alíquota de $10 \mathrm{ml}$ (correspondentes a $80 \mathrm{mg}$ do material sêco), transferiu-se para um balão de Erlenmeyer de $50 \mathrm{ml}$. Foram adicionados $7 \mathrm{ml}$ de água destilada, $2 \mathrm{ml}$ de solução de metavanadato de amônio $(1,25 \mathrm{~g}$ de $\mathrm{NH}_{4} \mathrm{VO}_{3}$ em $300 \mathrm{ml}$ de água em ebulição; esfriar, adicionar $175 \mathrm{ml}$ de $\mathrm{HNO}_{3}$ e completar a $500 \mathrm{ml}$ ), $1 \mathrm{ml}$ de solução de molibdato de amônio a $10 \%$, homogeneizou-se e depois de esperar 15 minutos, determinou-se a densidade ótica da solução, empregando o filtro de 415 a 440 milimicrons. Prèviamente, foram obtidas as densidades óticas de soluções com concentrações de fósforo conhecidas.

\section{CÁLCIO}

O cálcio foi determinado numa alíquota de $100 \mathrm{ml}$ da solução A (correspondentes a $800 \mathrm{mg}$ de material sêco) pelo método clássico da titulação, com permanganato de potássio, do ácido oxálico, procedente do oxalato de cálcio.

\section{MAGNÉSIO}

Este elemento foi determinado numa alíquotá de $1 \mathrm{ml} \mathrm{da}$ solução A e pelo método colorimétrico do tiazol amarelo, conforme descrevem YOUNG \& GILL (1951) e LOTT \& OUTROS (1956).

\section{ENXôFre}

O enxôfre foi determinado pelo método gravimétrico do $\mathrm{BaSO}_{4}$. 2,000 $\mathrm{g}$ do material' sêco foram tratados por $20 \mathrm{ml}$ de 
$\mathrm{HNO}_{3}$ em balão de Kjeldahl de $100 \mathrm{ml}$ e deixou-se digerir até a destruição completa da matéria orgânica. Juntaram-se $2 \mathrm{ml}$ da solução de $\mathrm{HC}^{\circ} \mathrm{O}_{4}$ a $70-72 \%$ e aqueceu-se até desprendimento de $\mathrm{HC} \mathrm{O}_{4}$. Foram adicionados $20-40 \mathrm{ml}$ de água destilada e filtrou-se para um copo de $400 \mathrm{ml}$, através de pape] Whatman n.o 1. Adicionou-se água destilada até um volume aproximado de $100 \mathrm{ml}$, aqueceu-se a ebulição e foram adicionados $10 \mathrm{ml}$ de solução de $\mathrm{BaC1}_{2}$ a $5 \%$. Deixou-se em repouso durante 1 hora à $60-70^{\circ} \mathrm{C}$ e filtrou-se o $\mathrm{BaSO}_{4}$ através de papel SS 589, faixa azul. Depois de lavar o precipitado convenientemente, foi o mesmo calcinado a $850-900^{\circ} \mathrm{C}$, durante 1 hora. A porcentagem foi calculada, mediante:

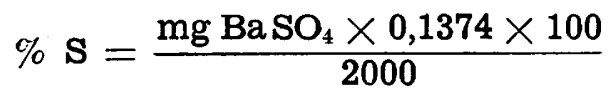

\section{3 - DADOS OBTIDOS E DISCUSSÃO}

\section{1 - Crescimento da Cana}

Em primeiro lugar, vão ser apresentados os valores obtidos para o pêso das fôlhas, dos colmos e total, de 4 touceiras de cana, com a idade de 6 a 15 meses. A sucessão dêsses pesos forneceu uma idéia do crescimento da cana em função de sua idade, conforme mostra o quadro 2.

As.$^{\mathrm{a}}$ e $2 .^{\mathrm{a}}$ colunas do quadro 2 mostram, respectivamente, o mês da coleta da amostra e a idade da cana em meses. Na 3. ${ }^{\mathrm{a}}, 4 .^{\mathrm{a}}$ e 5. ${ }^{\mathrm{a}}$ colunas são apresentados os pesos do material fresco, de fôlhas, colmos e total, de 4 touceiras do tratamento "sem adubo". As 6. a , 7.a e 8. a colunas fornecem o pêso do material sêco das mesmas partes anteriores do mesmo tratamento, isto é, "sem adubo". As 9. a, 10. a e 11.a colunas indicam o pêso do material fresco das fôlhas, colmos e total, do tratamento "adubado". Finalmente, as colunas 12. ${ }^{a}, 13 .^{a}$ e $14 .^{a}$ mostram o pêso do material sêco das mesmas partes anteriores e do mesmo tratamento.

Os dados do quadro 2 esclarecem que até o sexto mês de idade, o crescimento da cana, quer tenha sido adubada ou não, é relativamente pequeno, quando se consideram os pesos do material fresco ou do material sêco. No presente experimento, a cana apresentou um crescimento em pêso, pronunciado, a partir do oitavo mês de idade, isto é, depois de dezembro de 1956, até atingir o $12 .^{\circ}$ mês de idade, que no presente expe- 


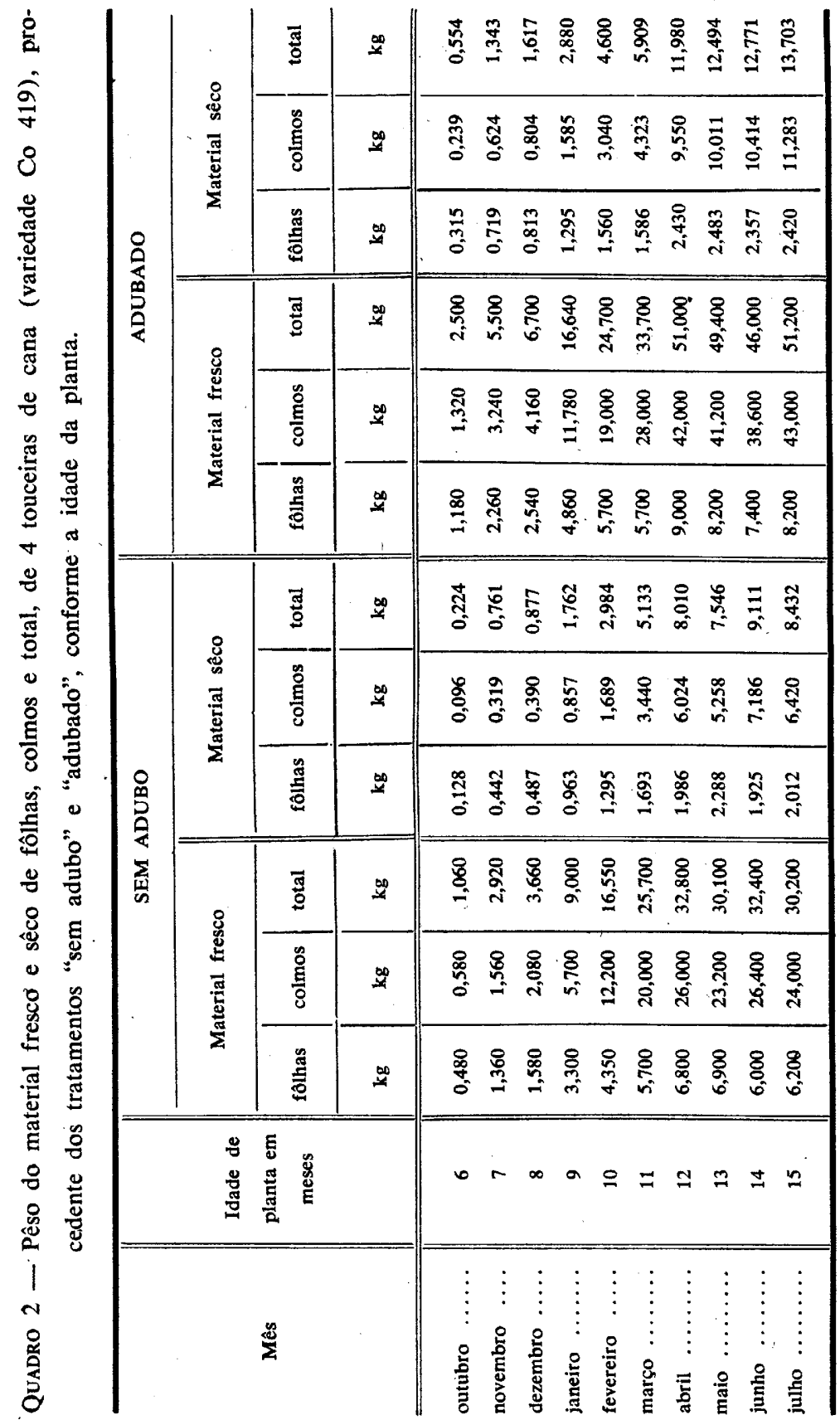




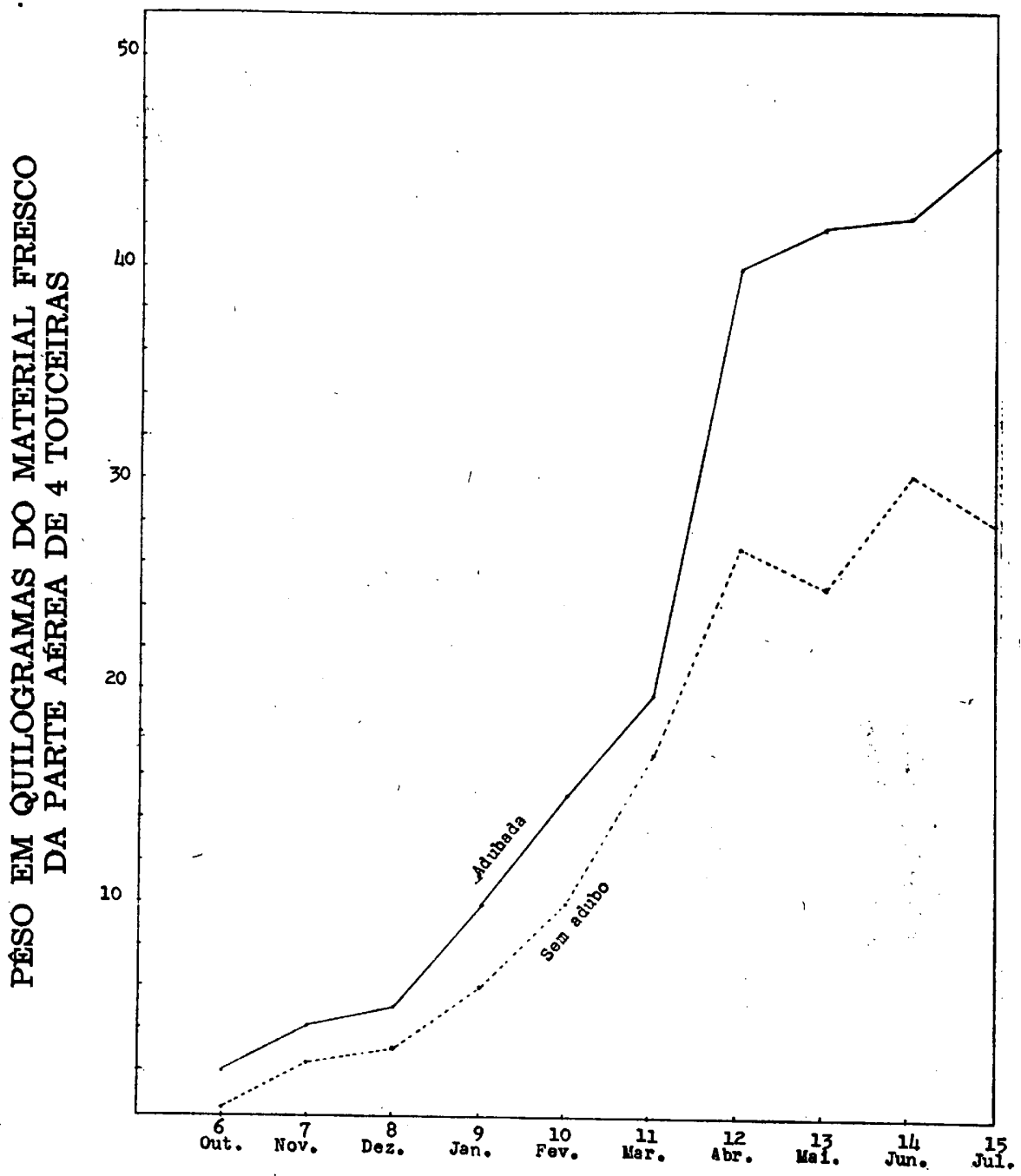

IDADE DA PLANTA EM MESES E DATA DA COLETA DA AMOSTRA

Figura 1 - Curva de crescimento em pêso de material fresco da cana Co 419, em função da idade. 


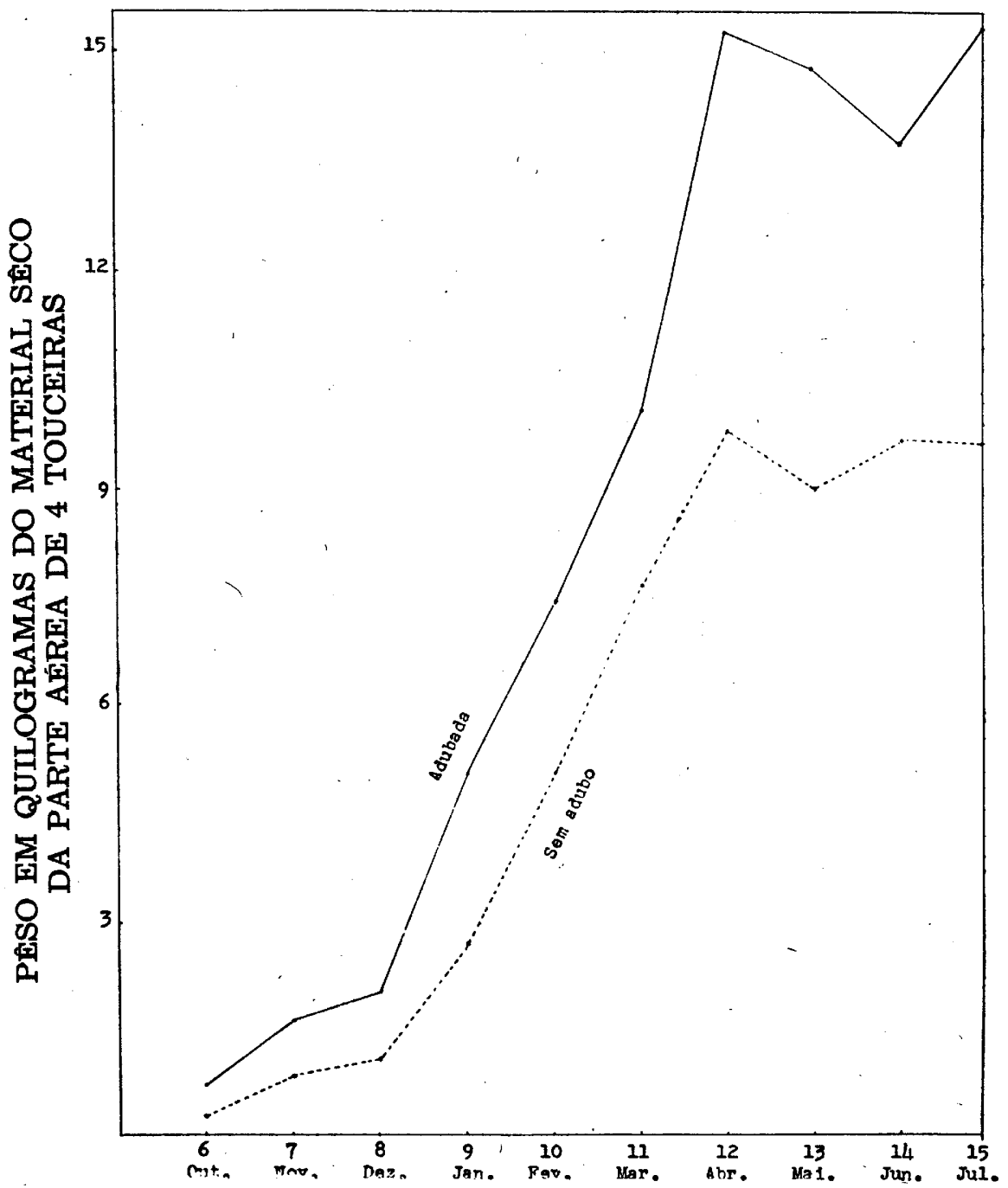

IDADE DA PLANTA EM MESES E DATA DA COLETA DA AMOSTRA

Figura 2 - Curva de crescimento em pêso de material sêco da cana Co 419, em função da idade. 
rimento, correspondeu a abril de 1957. Depois do $12:^{\circ}$ mês de idade, o crescimento estacionou, e ao atingir 15 mêses de idade, em julho de 1957, considerou-se terminado o experimento, uma vez que os dados analíticos obtidos para o caldo foram os seguintes:

\section{sem adubo adubada}

\begin{tabular}{llc} 
Brix $\ldots \ldots \ldots \ldots \ldots \ldots$ & 19,3 & \multicolumn{1}{c}{20,3} \\
Polarização $\ldots \ldots \ldots \ldots$ & 16,91 & 17,86 \\
Pureza $\ldots \ldots \ldots \ldots \ldots$ & 87,61 & 87,98 \\
Redutores $\ldots \ldots \ldots \ldots$ & 1,19 & 0,81
\end{tabular}

Uma visão mais geral do crescimento em pêso da cana poderá ser obtida através das figuras 1 e 2 . Na figura 1 acham-se apresentadas as curvas de crescimento em pêso total (fôlhas e colmos) do material fresco, da parte aérea de 4 touceiras de cana, em função da idade, dos tratamentos "sem adubo" e "adubada". Na figura 2, o aumento em pêso do material sêco, também de 4 touceiras.

Tanto na figura 1 , como na 2 , no eixo das ordenadas, estão representados quilogramas de material procedente da parte aérea de 4 touceiras completas. No eixo das abcissas estão representadas a idade da cana em meses $(6,7,8,9 \ldots$ etc.) e o mês da coleta da amostra (outobro, novembro, dezembro etc.).

E interessante observar que, no presente experimento, o crescimento da cana em função da idade, é representado por curvas de natureza sigmoide, conforme mostram as figuras 1 e 2.

Os dados do quadro 2 e as figuras 1 e 2 evidenciam que o efeito do adubo sốbre o crescimento da cana já se fez sentir, a partir do sexto mês de idade da planta (outubro, no presente experimento), mas acentuou-se, consideràvelmente, no $12 .^{\circ}$ mês (abril neste experimento), quando levadas em conta as diferenças absolutas.

Usando os dados do quadro 2, e fazendo-se o pêso do material sêco de 4 touceiras completas (fôlhas e colmos), aos 15 meses de idade, do tratamento "adubado", como 100 $(13,703 \mathrm{~kg}=100)$, obteve-se a curva porcentual do cresci- 


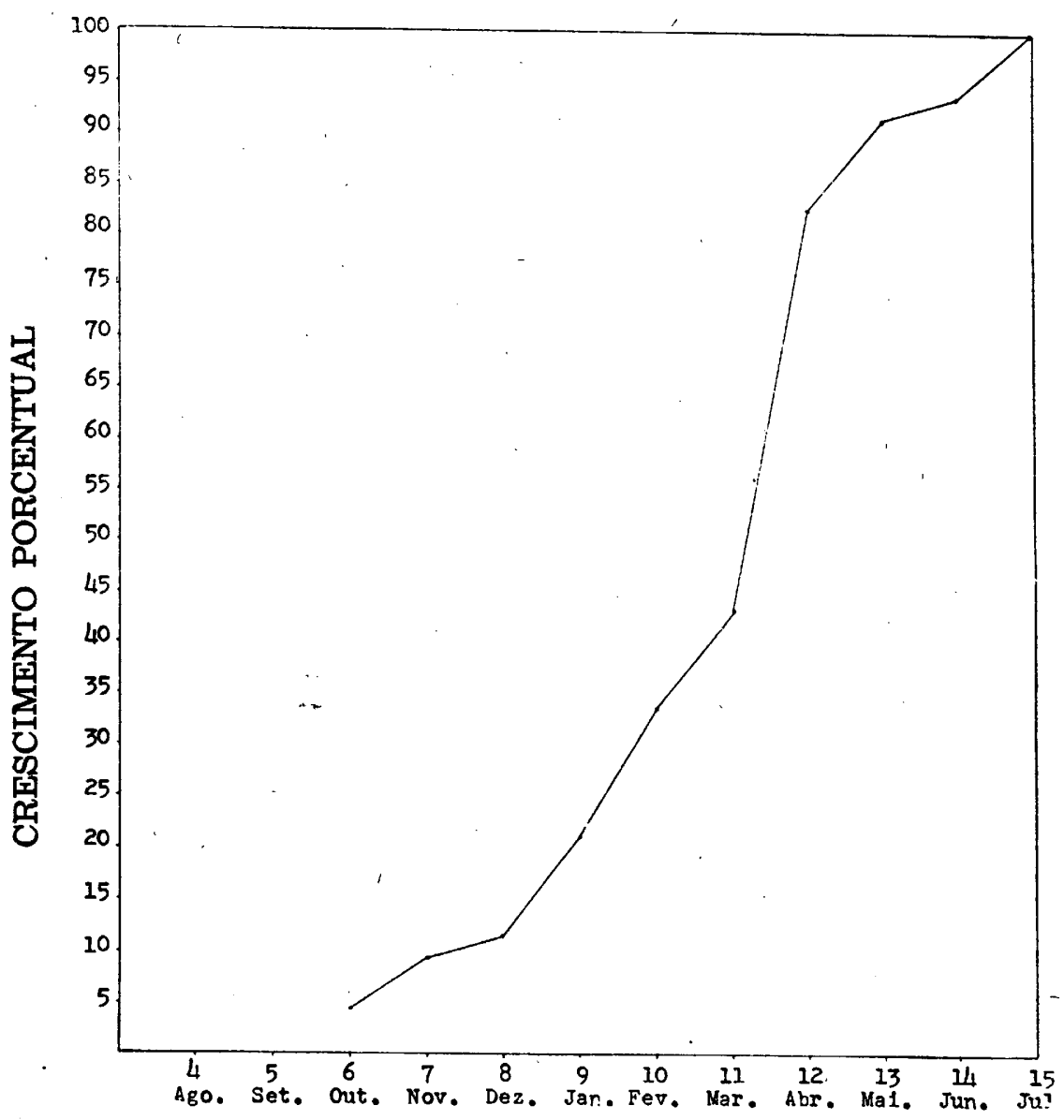

IDADE DA PLANTA EM MESES, E DATA DA COLETA DA AMOSTRA

Figura 3 - Curva porcentual de crescimento do material sêco da cana, Co 419, do tratamento adubado, em função da idade. 
mento da cana em função de sua idade, conforme representa a figura 3.

Na figura 3, no eixo das ordenadas, está representado o crescimento porcentual do material sêco da parte aérea (fôlhas e colmos) de 4 touceiras, considerando o pêso obtido aos 15 mêses de idade, igual a 100 . No eixo das abcissas, estão representadas a idade da planta em meses $(4,5,6,7 \ldots$ etc.) e o mês da coleta do material (agôsto, setembro, etc.).

Conforme mostra a figura 3 , até os seis meses de idade (outubro de 1956, neste experimento) o crescimento da cana, representado pelo pêso do material sêco da sua parte aérea, nẫo alcançou $5 \%$ do pêso apresentado aos 15 meses de idade. Aos 9 meses de idade (janeiro de 1957 no presente experimento), o erescimento em pêso da cana foi de $21 \%$ do pêso atingido aos 15 meses de idade. O maior acréscimo porcentual foi alcançado do $11 .^{\circ}$ para o $12 .^{\circ}$ mês de idade da cana (de março'a abril de 1957 neste experimento) quando passou de $43 \%$ para $87 \%$, isto é, dobrou o pêso do. material sêco.

Deve ser salientado também, o efeito do adubo no crescimento da cana. Examinando os dados relativos ao pêso obtido do tratamento "sem adubo" e do "adubado", quer do material fresco, quer do sêco, observa-se um efeito marcante do adubo, desde os 6 mêses até os 15 meses de idade da cana. Calculando-se o acréscimo porcentual do pêso obtido no tratamento adubado, em relação ao sem adubo, surgem os dados do Quadro 3.

QuADRo 3 - Acréscimo porcentual em pêso de cana do tratamento "adubado", em relação ao "sem adubo".

\begin{tabular}{|c|c|c|}
\hline \multirow{2}{*}{$\begin{array}{l}\text { Idade da planta } \\
\text { em meses }\end{array}$} & \multicolumn{2}{|c|}{$\begin{array}{l}\text { Acréscimo porcentual do pêso da cana do tratamento } \\
\text { adubado em relação ao sem adubo }\end{array}$} \\
\hline & Material fresco $\%$ & Material sêco \% \\
\hline $\begin{array}{r}6 \\
7 \\
8 \\
9 \\
10 \\
11 \\
12 \\
13 \\
14 \\
15\end{array}$ & $\begin{array}{r}135,8 \\
88,3 \\
83,0 \\
84,8 \\
49,2 \\
31,1 \\
46,5 \\
64,1 \\
41,9 \\
69,5\end{array}$ & $\begin{array}{r}147,3 \\
76,4 \\
84,3 \\
63,4 \\
54,1 \\
15,1 \\
49,5 \\
65,5 \\
40,1 \\
62,5\end{array}$ \\
\hline
\end{tabular}


Conforme mostram os dados do quadro 3, o acréscimo porcentual, determinado pelos fertilizantes, foi mais pronunciado no período compreendido entre o 6.0 e o $8 .^{\circ}$ ou $9 .^{\circ}$ mês de idade, do que no restante. Entretanto, deve ser observado que o acréscimo do pêso da cana, produzido pelo adubo aos 15 mêses de idade da planta (época de maturação da cana no presente experimento), foi muito elevado.

\section{2 - Variação da concentração dos elementos}

Os dados obtidos sôbre a concentração dos elementos, nas fôlhas e nos colmos do material sêco dos tratamentos "sem adubo" e "adubado", acham-se nos quadros 4 e 5, respectivamente.

Nos quadros 4 e 5, a primeira coluna fornece o mês da coleta do material e a segunda coluna a idade da planta em meses." Nas demais colunas aparecem os diversos elementos com duas sub-colunas cada um, contendo os dados obtidos nas fôlhas e no colmo.

Tanto no tratamento sem adubo (quadro 4), como no adubado (quadro 5), observa-se uma tendência de decréscimo na concentração dos diversos elementos no colmo, com o desenvolvimento da idade da planta. Entretanto, nas fôlhas, alguns elementos apresentaram uma tendência de crescer com a idade da planta, como o enxôfre e o silício. Outros, como o cálcio e o magnésio não apresentaram grande variação nas concentrações, conforme a idade da cana. Finalmente, o nitrogênio, fósforo e potássio, parecem decrescer no início e depois crescer um pouco com o desenvolvimento da planta.

Observa-se também, que, para os elementos nitrogênio, fósforo e cálcio, a planta apresentou uma concentração mais elevada nas fôlhas, do que nos colmos, em tôdas as amostras, isto é, de 6 a 15 mêses de idade. Quanto ao potássio, o colmo apresentou um teor mais elevado do que as fôlhas, do $6 .^{\circ}$ ao $9 .^{\circ}$ mês de idade, nos dois tratamentos. Depois do $9 .^{\circ}$ mês de idade, as fôlhas se mostraram sempre mais ricas do que o colmo, no citado elemento. Para o magnésio, a tendência seguida foi similar a do potássio.

O enxôfre ocorreu em maior porcentagem no côlmo do que nas fôlhas, do $6 .^{\circ}$ ao $8 .^{\circ}$ ou 9.0 mês de idade, nos dois tratamentos, isto é, no tratamento "sem adubo" e "adubado". Do $8 .^{\circ}$ ou $9 .^{\circ}$ mês em diante, as fôlhas se mostraram sempre mais ricas que o côlmo, em ambos tratamentos. 


\begin{tabular}{|c|c|c|}
\hline \multirow{2}{*}{$\begin{array}{l}\bar{n} \\
\therefore\end{array}$} & $\stackrel{\circ}{8}$ & 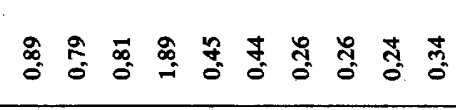 \\
\hline & 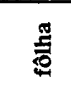 & 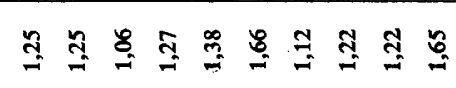 \\
\hline \multirow[b]{2}{*}{$\therefore$} & $\begin{array}{l}0 \\
\frac{0}{8} \\
\end{array}$ & 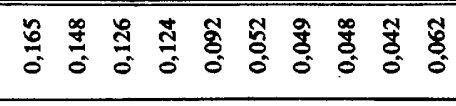 \\
\hline & 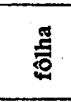 & 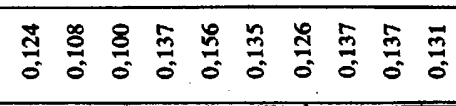 \\
\hline \multirow{2}{*}{$\sum_{0}^{\infty}$} & $\frac{0}{8}$ & 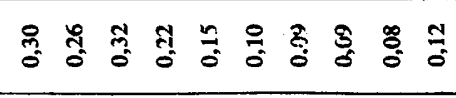 \\
\hline & 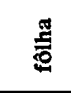 & 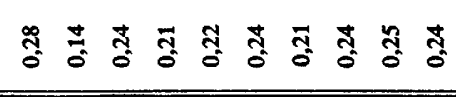 \\
\hline \multirow{2}{*}{ ๕̊ } & 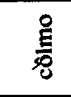 & 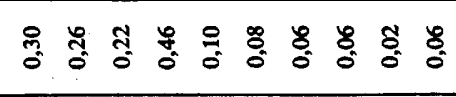 \\
\hline & 急 & 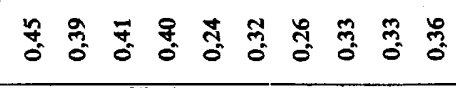 \\
\hline \multirow{2}{*}{ 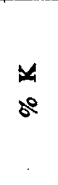 } & 喜 & 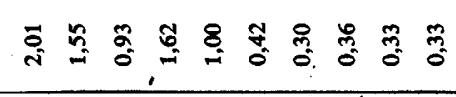 \\
\hline & 悉 & 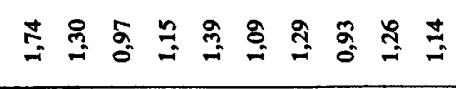 \\
\hline \multirow{2}{*}{ : } & 善 & 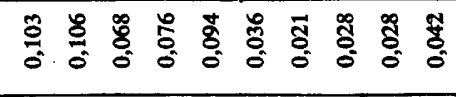 \\
\hline & 善 & 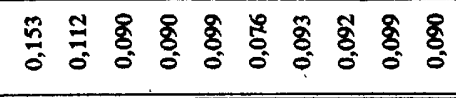 \\
\hline \multirow{2}{*}{$\begin{array}{l}z \\
a\end{array}$} & 兽 & 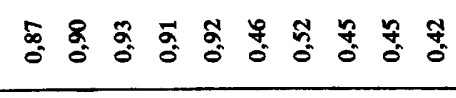 \\
\hline & 趝 & : \\
\hline \multicolumn{2}{|c|}{ 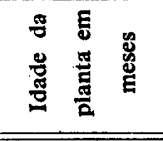 } & $0+\infty a s= \pm 0$ \\
\hline & 2 & 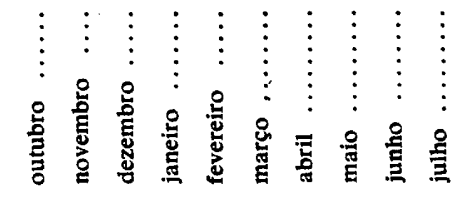 \\
\hline
\end{tabular}




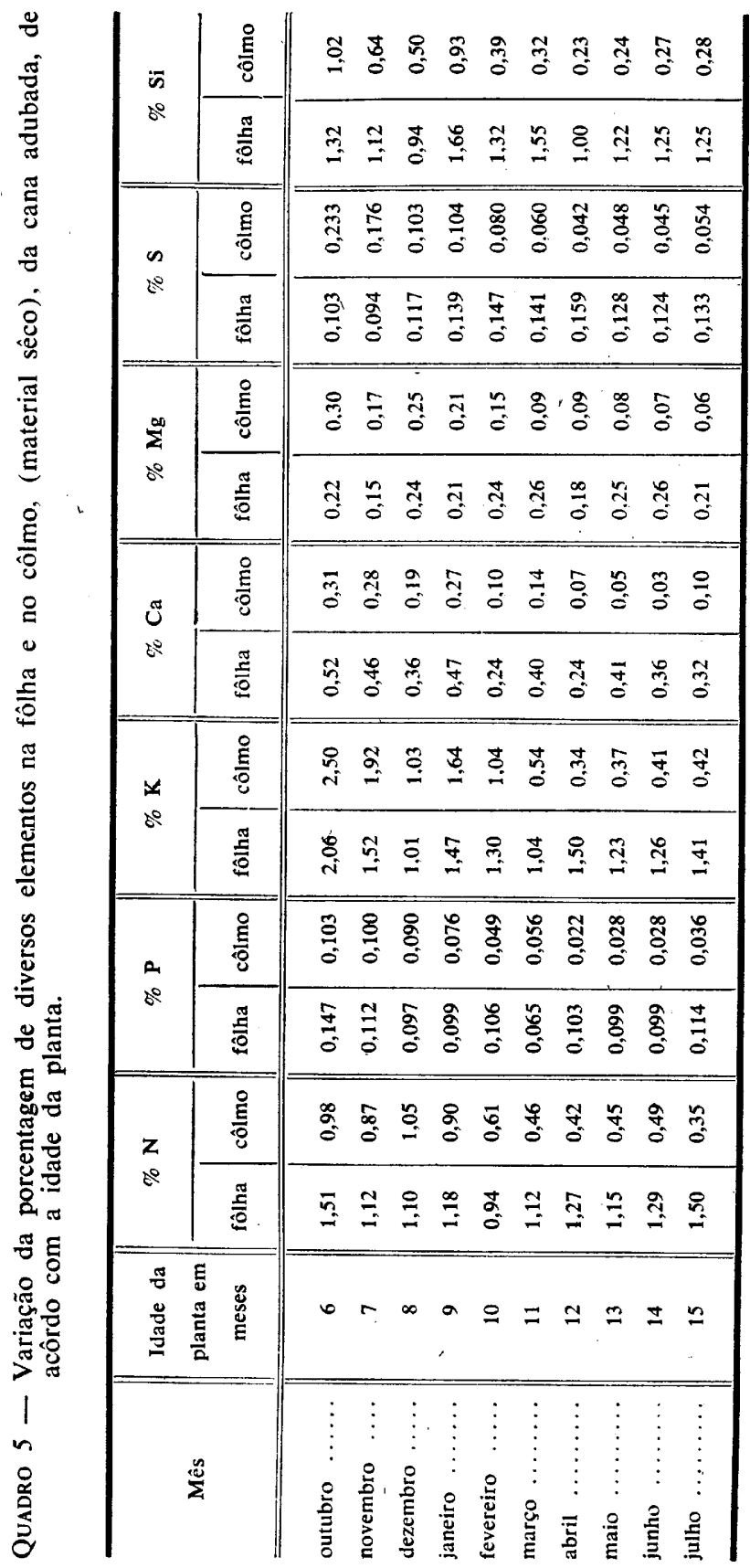


Comparando os dados dos quadros 4 e 5, observa-se que; em muitos casos, o material procedente do tratamento sem adubo apresentou um teor mais elevado num ou vários elementos, do que o material oriundo do tratamento adubado. O fenômeno em aprêçd encontra explicação no elevado aumento porcentual do pêso da cana adubada, em relação à não adubada. Como a cana procedente do tratamento adubado apresentou uma quantidade muito maior de material sêco do que a cana proveniente do tratamento sem adubação, os elementos nutridores sofreram uma "diluição" mais intensa no primeiro caso.

\section{3 - Quantidade de elementos absorvidos}

A quantidade em gramas, de nitrogênio, fósforo, potássio, cálcio, magnésio, enxôfre e silício absorvida por 4 touceiras, em função da idade da planta, acha-se resumida no quadro 6.

No quadro 6 , na $1 .^{\text {a }}$ coluna, estão representados os mêses do ano em que foram colhidas as amostras, e na 2.a coluna, a idade da planta em mêses. Nas colunas restantes, são apresentadas as quantidades em gramas absorvidas dos diversos elementos, que aparecem em duas sub-colunas, designadas por $s$ e $a$, significando "sem adubo" e "adubada", respectivamente.

A absorção dos diversos elementos pela cana, tanto do tratamento sem adubo, como do adubado, acentuou-se, notàvelmente, a partir de janeiro e fevereiro, isto é, quando a planta apresentava 9 a 10 meses de idade, até abril e maio, isto é, quando a planta apresentava 12 a 13 meses de idade.

A partir de 12 a 13 meses de idade (abril e maio), a intensidade da absorção dos divers̀os elementos estacionou, evidenciando, que no presente experimento, houve um período de absorção de nutrientes mais intenso, compreendido entre o 9.0-10.0 mês de idade (outubro-novembro) e o $12 .^{\circ}-13.0^{\circ}$ mês de idade (abril-maio). Como consequência, deve-se concluir que uma grande quantidade de elementos nutritivos deve estar disponível para a cana, no citado período, isto é, do 9.0-10.0 ao $12 .^{\circ}-13 .^{\circ}$ mês de idade.

Examinando os dados do quadro 6, nota-se que, em muitos casos, a quantidade de diversos elementos absorvidos num determinado mês é inferior à absorvida no mês anterior. Esta anomalia pode ter como causa diversos fatôres, mas, talvez, o principal resida na heterogeneidade do próprio material. 


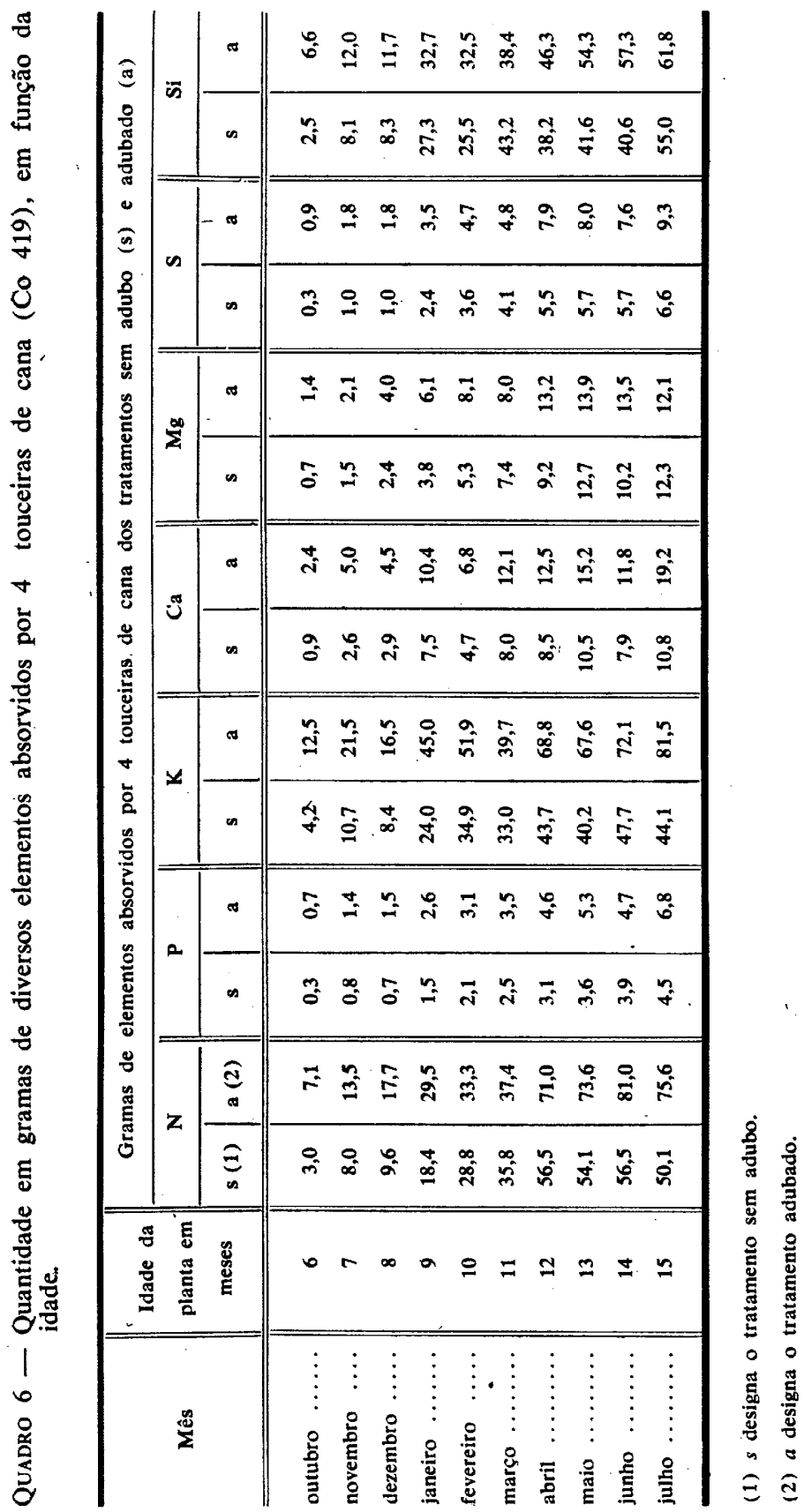


Devem ainda ser salientadas algumas observações de maior importância. Assim, em primeiro lugar as quantidades relativamente grandes de $\mathrm{N}$ e $\mathrm{K}$ absorvidas pelas 4 touceiras do tratamento adubado. Tomando-se os maiores valores, obtem-se $81,0 \mathrm{~g}$ de $\mathrm{N}$ (14. $\mathrm{mês}), 81,5 \mathrm{~g}$ de $\mathrm{K}$ (15. $\mathrm{mês}$ ) e $61,8 \mathrm{~g}$ de $\mathrm{Si}$ (15.0 mês). Em seguida, vêm Ca com 19,2 $\mathrm{g}$ (15.0 mês), $\mathrm{Mg}$ com $13,9 \mathrm{~g}$ (13. ${ }^{\circ}$ mês), $\mathrm{S}$ com $9,3 \mathrm{~g}$ (15.0 mês) e $\mathrm{P}$ com $6,8 \mathrm{~g}$ ( $15.0^{\circ}$ mês). $\mathrm{E}$ interessante observar que $\mathrm{P}$ foi absorvido em menor quantidade que o $\mathrm{Ca}, \mathrm{Mg}$ e mesmo $\mathrm{S}$, quando os mencionados nutrientes são expressos na sua forma elementar. Finalmente, é, sem dúvida, digna de observação, a elevada quantidade de Si absorvida pela cana, ainda que êste elemento não seja essencial aos vegetais.

\section{4 - RESUMO E CONCLUSOES}

O presente trabalho tem por objetivo o estudo do crescimento da cana de açúcar, variedade Co 419 e a absorção de nitrogêncio, fósforo, potássio, cálcio, magnésio, enxôfre e silício, em função da idade da planta e nas condições de clima e solo de Piracicaba, Estado de São Paulo.

Em abril de 1956, foi instalado um experimento na Estação Experimental de Cana, "Dr. José Vizioli", em Piracicaba, com a variedade co 419 , e que constou de 2 tratamentos, com 3 repetições. Um dos tratamentos foi denominado "sem adubo", isto é, a cana não foi adubada. O outro tratamento foi designado "adubado", porque na época do plantio da cana foram aplicados, por hectare, $40 \mathrm{~kg}$ de $\mathrm{N}$ (em forma de sulfato de amônio), $100 \mathrm{Kg}$ de $\mathrm{P}_{2} \mathrm{O}_{5}$ (na forma de superfosfato simples) e $40 \mathrm{Kg}$ de $\mathrm{K}_{2} \mathrm{O}$ (na forma de cloreto de potássio).

A partir de outubro de 1956, até julho de 1957, isto é, dos 6 meses até os 15 meses de idade, foram coletadas, mensalmente, as amostras de cana do campo. As amostras, constituidas de tôda a parte aérea de 4 touceiras completas de cada tratamento, depois de pesadas, foram preparadas para a análise. Foram determinados nos colmos e fôlhas os seguintes teores: $\%$ água, $\% \mathrm{~N}, \% \mathrm{P}, \% \mathrm{~K}, \% \mathrm{Ca}, \% \mathrm{Mg}, \% \mathrm{~s}$ e $\% \mathrm{Si}$.

Os dados obtidos permitem tirar as seguintes conclusões:

a) O crescimento da cana, nas condições de clima e solo que prevaleceram neste experimento foi pouco intenso até os 6 meses de idade da cultura, não tendo alcançado $5 \%$ do pêso 
total do material sêco, quando a planta atingiu a maturação. O crescimento em pêso da cana tornou-se bem pronunciado, a partir do $8 .^{\circ}$ mês de idade (dezembro de 1956), e estacionou a partir do $12 .^{\circ}$ mês de idade (abril de 1957).

b) $\mathrm{O}$ efeito do adubo no crescimento em pêso da cana foi marcante e perceptível do início ao fim do experimento. Aos 15 meses de idade, quando se processou a colheita, a cana adubada apresentou um acréscimo em pêso de $69,5 \%$, em relação à sem adubo, calculando-se no material fresco, tal como vem do campo. Calculando-se no material sêco, o acréscimo foi de $62,5 \%$.

c) A concentração da maioria dos elementos na planta (côlmo e fôlhas) decresceu com a idade da mesma. Fizeram exceção o magnésio, silício e enxôfre, cujas concentrações nas fôlhas não se modificaram sensivelmente.

d) O nitrogênio, fósforo e cálcio se apresentaram em concentração mais elevada nas fôlhas, do que nos colmos, dos 6 aos 15 meses de idade da planta. O potássio se apresentou com um teor mais elevado no côlmo do que nas fôlhas, do $6 .^{\circ}$ ao $9 .^{\circ}$ mês de idade; depois do $90^{\circ}$ mês de idade, as fôlhas se mostraram sempre mais ricas do que o côlmo. O magnésio seguiu a tendência de variação do potássio e o enxôfre seguiu em parte.

e) Vários elementos se apresentaram com concentração mais elevada no tratamento sem adubo do que no adubado, tanto no côlmo como nas fôlhas. Este fato pode ser explicado, levando-se em conta que a cana adubada produziu muito mais material sêco, o que determinou uma "diluição" maior dos diversos elementos.

f) A absorção dos diversos elementos pela cana, tanto do tratamento sem adubo, como do adubado, acentuou-se a partir dos 9-10. ${ }^{\circ}$ meses de idade (janeiro-fevereiro) até 12-13.0 meses de idade (abril-maio). A partir do 12-13.0 meses de idade, a intensidade de 'absorção estacionou, evidenciando que no presente experimento, houve um período de absorção de nutrientes muito intenso, compreendido entre $9-100^{\circ} \mathrm{e}$ 12-13..$^{\circ}$ ês de idade. Como consequência, dève-se concluir que, uma grande quantidade de elementos nutritivos deve estar disponível para a cana no período compreendido entre $9-100^{\circ}$ e $12-130^{\circ}$ mês de idade. 
g) As quantidades máximas absorvidas dos diferentes elementos por 4 touceiras de cana, foram:

$\begin{array}{lr}\text { Nitrogênio: } & 81,0 \mathrm{~g} \text { de } \mathrm{N} \\ \text { Fósforo: } & 6,8 \mathrm{~g} \text { de } \mathrm{P} \\ \text { Potássio: } & 81,5 \mathrm{~g} \text { de } \mathrm{K} \\ \text { Cálcio: } & 19,2 \mathrm{~g} \text { de } \mathrm{Ca} \\ \text { Magnésio: } & 13,9 \mathrm{~g} \text { de } \mathrm{Mg} \\ \text { Enxôfre: } & 9,3 \mathrm{~g} \text { de } \mathrm{S} \\ \text { Silício: } & 61,8 \mathrm{~g} \text { dè } \mathrm{Si}\end{array}$

E interessante observar que o fósforo foi absorvido em menor quantidade que o cálcio, magnésio e mesmo o enxôfre. Também é digna de observação a elevadla quantidade de silício absorvida pela cana, apesar dêste elemento não ser essencial.

\section{5 - SUMMARY}

THE UPTAKE OF NITROGEN, PHOSPHORUS, POTASSIUM, CALCIUM, MAGNESIUM, SULFUR AND SILICON BY SUGAR CANE, VARIETY Co 419, AND ITS GROWTH ACCORDING TO THE AGE OF THE PLANT.

This paper describes the data obtained for the growth of sugar cane, variety Co 419 , and the amount and rate of absorption of nitrogen, phosphorus, potassium, calcium, magnesium, sulfur, and silicon, according to the age of the plant, in the soil and climate conditions of the state of $\mathbf{S}$. Paulo, Brazil.

An experiment was installed in the Estação Experimental de Cana de Açúcar "Dr. José Vizioli", at Piracicaba, state of S. Paulo, Brazil, and the soil "tèrra-roxa misturada" presented the following composition:

Sand (more than $0,2 \mathrm{~mm}$ ) $\ldots \ldots \ldots \ldots \ldots \ldots .8 .40 \%$

Fine sand (from 0,2 to less than $0,02 \mathrm{~mm}$ ) ... $24.90 \%$

Silt (from 0,02 to less than $0,002 \mathrm{~mm}$ ) $\ldots \ldots \ldots 16.40 \%$

Clay (form $0,002 \mathrm{~mm}$ and less) $\ldots \ldots \ldots \ldots \ldots, 50.20 \%$

$\mathrm{pH} 10 \mathrm{~g}$ of soil and $25 \mathrm{ml}$ of distilled water) $\ldots . \quad 5.20$ 
$\% \mathrm{C}$ (g of carbon per $100 \mathrm{~g}$ of soil) $\ldots \ldots \ldots \ldots \ldots \quad 1.00$

$\% \mathrm{~N}$ (g of nitrogen per $100 \mathrm{~g}$ of soil) $\ldots \ldots \ldots \ldots .0 .15$

$\mathrm{PO}_{4}{ }^{-3}$ (me. per $100 \mathrm{~g}$ of soil, soluble in 0,05 normal $\left.\mathrm{H}_{2} \mathrm{SO}_{4}\right) \ldots \ldots \ldots \ldots \ldots \ldots \ldots \ldots \ldots \ldots \ldots \ldots . \ldots \ldots$

$\mathrm{K}^{+}$(exchangeable, me. per $100 \mathrm{~g}$ of soil) $\ldots \ldots \ldots \quad 0.18$

$\mathrm{Ca}^{+2}$ (exchangeable, me. per $100 \mathrm{~g}$ of soil) $\ldots . .2 .00$

$\mathrm{Mg}^{+2}$ (exchangeable, me. per $100 \mathrm{~g}$ of soil) $\ldots \ldots \quad 0.66$

The monthly rainfall and mean temperature from January 1956 to August 1957 are presented in Table 1, in Portuguese.

The experiment consisted of 3 replications of the treatments: without fertilizer and with fertilizer $(40 \mathrm{Kg}$ of $\mathrm{N}$, from ammonium sulfate; $100 \mathrm{Kg}$ of $\mathrm{P}_{2} \mathrm{O}_{5}$ from superphosphate and $40 \mathrm{Kg} \mathrm{K}_{2} \mathrm{O}$, from potassium chloride).

Four complete stools (stalks and leaves) were harvested from each treatment, and the plants separated in stalks and leaves, weighed, dried and analysed every month from 6 up to 15 months of age.

The data obtained for fresh and dry matter production are presented in table 2, and in figure 1 and 2, in Portuguese. The curves for fresh and dry matter production showed that fertilized and no fertilized sugar cane with 6 months of age presents only $5 \%$ of its total weight at 15 months of age. The most intense period of growth in this experiment is located, between 8 and 12 months of age, that is between December 1956 and April 1957. The dry matter production of sugar cane with 8 and 12 months of age was, respectively, 12,5\% and $87,5 \%$ of the total weight at 15 months of age.

The growth of sugar cane in relation to its age follows a sigmoid curve, according to the figures 1,2 and 3 .

The increase of dry matter production promoted by using fertilizer was $62,5 \%$ when sugar cane was 15 months of age.

The concentration of the elements (tables 4 and 5 in Portuguese) present a general trend of decreasing as the cane grows older. In the stalks this is true for all elements studied in this experiment. But in the leaves, somme elements, like sulfur and silicon, appears to increase with the increasing of age. Others, like calcium and magnesium do not show large variations, and finally a third group, formed by nitrogen, phosphorus and potassium seems to decrease at the beginning and later presents a light increasing. 
The concentration of the elements was higher in the leaves than in the stalks from 6 up to 15 months of age. There were some exceptions. Potassium, magnesium and sulfur were higher in the stalks than in the leaves from 6 up to 8 or 9 months of age. After 9 months, the leaves presented more potassium, magnesium and sulfur than the stalks.

The percentage of nitrogen in the leaves was lower in the plants that received fertilizer than in the plants without fertilizer with $6,7,8,10,11$ and 13 months of age. This can be explained by "dilution effect".

The uptake of elements by 4 stools (stalks and leaves) of sugar cane according to the plant age is showed in table 6, in Portuguese. The absorption of all studied elements, nitrogen, phosphorus, potassium, calcium, magnesium, sulfur and silicon, was higher in plants that received fertilizer.

The trend of uptake of nitrogen and potassium is similar to the trend of production of dry matter, that is, the maximum absorption of those two nutrients occurs between 9 and 13 months of age.

Finaly, the maxima amounts of elements absorbed by 4 stools (stalks and leaves) of sugar cane plants that received fertilizer are condensed in the following table:

\begin{tabular}{l||c|c}
\hline Element & $\begin{array}{l}\text { Maximum absorption } \\
\text { in grams }\end{array}$ & $\begin{array}{l}\text { Age of the plants } \\
\text { in months }\end{array}$ \\
\hline \hline Nitrogen (N) & 81.0 & 14 \\
Phosphorus (P) & 6.8 & 15 \\
Potassium (K) & 81.5 & 15 \\
Calcium (Ca) & 19.2 & 15 \\
Magnesium (Mg) & 13.9 & 13 \\
Sulfur (S) & 9.3 & 15 \\
Silicon (Si) & 61.8 & 15 \\
\hline
\end{tabular}

It is very interesting to note the low absorption of phosphorus even with $100 \mathrm{~kg}$ of $\mathrm{P}_{2} \mathrm{O}_{5}$ per hectare, aplied as superphosphate. The uptake of phosphorus was lower than calcium, magnesium and sulfur. Also, it is noteworthy the large amount of silicon absorbed by sugar cane. 


\section{6 - AGRADECIMENTO}

Os autores agradecem à $1 .^{\text {a }}$ Cadeira, Física e Meteorologia, pelo fornecimento dos dados relativos à queda pluviométrica e temperatura, apresentados nêste trabalho.

\section{7 - LITERATURA CITADA}

BOLTZ, D. F. \& C. H. LUECK, 1958 - Phosphorus. Em Boltz, D. F. editor. Colorimetric determination of nonmetals. Interscience $\mathrm{Pu}$ blishers, New York. pp. 29-46.

CAPÓ, B. G., G. SAMUELS \& OUTROS, 1955 - The method of foliar diagnosis as applied to sugarcane. Bulletin 123. Agr. Sta. Univ. of Puerto Rico. $47 \mathrm{pg}$.

CATANI, R. A., 1954 - A determinação do potássio pelos métodos do cobaltihexanitrito e de fotometria de chama; sua aplicação no estudo do potássio nos solos do Estado de S. Paulo. Tese, 145 pg. E. S. A. "Luis de Queiroz".

CATANI, R. A. \& F. R. PUPO DE MORAES, 1958 - A composição química do cafeeiro. Quantidade e distríbuição de $\mathrm{N}, \mathrm{P}_{2} \mathrm{O}_{5}, \mathrm{~K}_{2} \mathrm{O}$, CaO e $\mathrm{MgO}$ em cafeeiro de 1 a 5 anos de idade. Rev. Agricultura, 33: 45-52.

CLEMENTS, H. F., 1951 - Environmental influences of the growth of sugar cane. Em Mineral Nutrition of Plants. Editado por E. Truog. pg. 451-469. The University of Wisconsin Press.

CLEMENTS, H. F., 1955 - El registro agronomico em la Caña de Azucar de Ocidente. Yaritagua, Venezuela.

COURY, T., E. MALAVOLTA \& OUTROS, 1957 - A diagnose foliar na cana de açúcar. I. - Resultados preliminares. 28 pg. (Publicação avulsa sem referência de editora).

EVANS, H., 1955 - Studies in the mineral nutrition of sugar cane in British Guiana. Trop. Agric. 34: 395-322 (Separata).

KITSON, R. E. \& M. G. MELLON, 1944 - Colorimetric determiation of phosphorus as molybdivanadophosphoric acid. Ind. Eng. Chem. Anal. Ed. 16: 379-383.

KOENIG, R. A. \& C. R. JOHNSON, 1942 - Colorimetric determination of phosphorus in biological materials. Ind. Eng. Chem. Anal. Ed. 14: $155-156$.

LOTT, W. L., J. P. NERY \& J. R. GALLO, 1956 - A técnica de análise foliar aplicada ao cafeeiro. Boletim n. $79,29 \mathrm{pg}$. Instituto Agronômico, Campinas, Est. de S. Paulo.

VAN DILLEWIJN, C., 1952 - Botany of sugarcane. Waltham, Mass., The Chronica Botanica Co. XXIII, $371 \mathrm{pg}$.

YOUNG, H. Y. \& R. F. GIIL, 1951 - Determination of magnesium in plant tissue with thiazole yellow. Anal. Chem. 23: 751-754. 